\title{
Management of Potato Late Blight in the Peruvian Highlands: Evaluating the Benefits of Farmer Field Schools and Farmer Participatory Research
}

\author{
O. Ortiz, International Potato Center (CIP), Apartado 1558, Lima 12, Peru; K. A. Garrett and J. J. Heath, Depart- \\ ment of Plant Pathology, Kansas State University, Manhattan 66506; R. Orrego, International Potato Center (CIP), \\ Peru; and R. J. Nelson, Department of Plant Pathology, Cornell University, Ithaca, NY 14853
}

\begin{abstract}
Ortiz, O., Garrett, K. A., Heath, J. J., Orrego, R., and Nelson, R. J. 2004. Management of potato late blight in the Peruvian highlands: Evaluating the benefits of farmer field schools and farmer participatory research. Plant Dis. 88:565-571.

Farmer field school programs incorporating farmer participatory research (FPR-FFS) have the potential to provide important benefits to their participants and to other farmers who benefit from improved cultivars and management techniques. An FPR-FFS program in San Miguel, Cajamarca, Peru, has been in place since 1999 with an emphasis on management of potato late blight, caused by Phytophthora infestans, the most important problem facing Andean potato growers. Farmers' knowledge of late blight was surveyed to determine useful components for the FPR-FFS curriculum. The benefits to participants of FPR-FFS programs were evaluated first by measuring knowledge of late blight management of participants and nonparticipants. Studies of the Peruvian FPR-FFS program indicate that participants are more knowledgeable and that their expertise further increases after an additional year of participation. The benefits to participants can be evaluated more directly by comparing the productivity of participants' farms compared with nonparticipants' farms. For the Peruvian FPR-FFS program, participants had significantly higher average levels of productivity. The benefits of FPR-FFS programs for the development of better cultivars and management techniques can be evaluated indirectly in terms of improved estimates of performance. Estimates of the overall performance of a particular cultivar or technique become more precise as data from more sites are included in calculating the estimate. A more direct evaluation of benefits from FPR-FFS input may be based on the ability of farmers in FPR-FFS programs to eliminate undesirable genotypes and to recommend desirable genotypes based on criteria in addition to those used by breeders.
\end{abstract}

Farmer field schools (FFS) originally were developed for rice in Asia by the Food and Agriculture Organization of the United Nations (FAO) for teaching integrated pest management. These were season-long courses involving 25 farmers and a trained facilitator. The main focus was

Corresponding author: K. A. Garrett

E-mail: kgarrett@ksu.edu

Current address of J. J. Heath: Department of Entomology, Pennsylvania State University, University Park 16802.

This material is based upon work supported in part by the International Fund for Agricultural Development, by the OPEC Fund for International Development, by CARE-Peru, by the U.S. National Science Foundation under Grant No. DEB0130692, by NSF Grant No. EPS-9874732 with matching support from the State of Kansas, and by Regional Research Funds from North Central Project NC-125. This is Kansas State Experiment Station Contribution No. 04-054-J.

Accepted for publication 28 August 2003.

Publication no. D-2004-0206-040

(C) 2004 The American Phytopathological Society promoting learning by discovery, which included hands-on training activities such as insect zoos and the use of field experiments to compare integrated pest management (IPM) strategies with farmers' practices. Later, diseases such as rice blast also were addressed $(8,11)$. More recently, the FFS model has been adapted to potato management in the Andes and other regions. Strategies for the management of potato disease problems such as late blight depend on local environmental conditions; therefore, control strategies need to be adjusted to the local environment. This is one reason why farmer participatory research (FPR) may be an important addition to the FFS model, because it encourages local experimentation to determine optimal management strategies. In Peru, the FFS approach was adapted with an emphasis on participatory research, particularly for testing promising resistant clones and fungicide strategies for late blight management. The Peruvian FFS have been described in more detail and in comparison to Asian field schools in a recent Plant Disease Feature (8). In this discussion, we will review the structure and features of the Peruvian FPR-FFS projects briefly and then emphasize the different types of benefits that might be achieved by FFS and FPR, and some approaches for evaluating the magnitude of these benefits.

With the support of the International Fund for Agricultural Development (IFAD) and the OPEC Fund for International Development, the International Potato Center (CIP) and partners implemented an FFS program between 1999 and 2002. Activities were undertaken in Peru and also in Bolivia, Ecuador, Uganda, Ethiopia, Bangladesh, and China. In the case of Peru, CIP established a collaborative agreement with the nongovernmental organization CAREPeru, which had experience with potato but had not utilized the FFS methodology. In Peru, FPR-FFS consisted of 15 to 25 farmers who worked with a facilitator, an extension worker trained in teaching, participatory research, and agricultural science. They usually met every 2 weeks, following a format structured around a field guide with learning and research activities. An experimental field was used as a central point for farmers to consider different management approaches. In addition to farmer participation in technology evaluation, farmers provided feedback for evaluation of the programs and improvement of the FFS methodology.

Potato late blight was a natural emphasis for the schools because it is the most important concern for potato growers in the Peruvian Andes. It is estimated that $15 \%$ of potato yield is lost directly to late blight, in addition to the cost of an average of six fungicide sprays per crop for adequate management (10). In a recent survey of farmers in Cajamarca, Contumaza, and San Miguel, Peru, late blight was perceived as the most important potato pest (10). Like many other plant diseases, late blight is challenging for farmers because of the complexity of the pathosystem, because the pathogen generally is not visible to the naked eye, and because the symptoms of the disease are not immediately visible due to a latent period. For late blight, both leaf and tuber blight are possible and the relationship between severity of leaf and tuber blight is complex. Although farmers generally have made extensive observations on 
insects and the symptoms of diseases, their ability to interpret these systems often is limited due to insufficient knowledge of underlying processes (2). Late blight can be especially difficult for farmers to manage. Epidemics are explosive. Currently, cultural controls are dependent on combination with other management techniques (4-6). Resistance is useful but still dependent on the use of fungicides for reliable management. The relative performance of cultivars can vary greatly, such that, under low disease pressure, all may appear resistant whereas, under high disease pressure, all appear susceptible. FPRFFS can act as both a source and recipient for new data about the performance of these management approaches and improvements to them.

As a first step in determining the content of the FPR-FFS curriculum, farmers were surveyed to determine their current level of understanding. Although levels of knowledge varied, most farmers did not know that late blight is caused by a microorganism (10), or about its dissemination and the factors that facilitate or slow disease progress. In general, small farmers in Peru have limited access to education and to formal extension services, and lack the appropriate skills for late blight diagnosis. Peruvian farmers tend to depend on information from their families, neighbors, and pesticide salespeople (9). Fungicide use is by far the most familiar control practice for late blight, but knowledge about different types of fungicides, doses, and appropriate use is rare (10).
In response to these gaps in the knowledge necessary to implement IPM programs, a representative set of FPR-FFS learning sessions was developed to include the following topics: (i) introduction and work plan: establishing the responsibilities of participants; (ii) principles of experimentation: the concepts of replication and randomization; (iii) seed quality and disease dissemination: the importance of high-quality seed; (iv) agroecological analysis: observing and analyzing fields for late blight progression; (v) insect and pathogen reproduction and dissemination; (vi) introduction to IPM: the general concept and types of control measures; (vii) fungicide use: types, doses, frequency; (viii) genetic resistance: the concept of resistance; (ix) production costs: comparing the costs and benefits of different pest control options; and (x) postharvest management: storage methods.

The addition of FPR components to FFS shifts the emphasis of the approach. FFS components include an informal adult education approach. FPR adds an emphasis on participatory research with the purpose of technology development and training. Research-extension partnerships are needed to fulfill farmer expectations, and also may make more efficient development interventions. For example, results of FPR-FFS provided the basis for CARE-Peru's decision to provide credit for farmer groups to purchase and multiply seed of the most promising cultivars and clones identified from FPR-FFS. In this program, research results were taken into account immediately within extension strategies. Local research networks shared work and data across communities through field days, workshops, and exchange visits.

FPR and FFS activities sometimes may be in conflict. For example, the experimental designs tested sometimes were found to be overly complex for training of farmers. Obtaining farmer input into the design of experiments was identified as an important objective. Participatory trials were adjusted because the experiments initially were too complex, the quality of participation in FPR was low, and improved methods for participatory data collection and sharing were needed. Midterm corrections for improvement of the FPR included improvement of FFS educational activities, such as methods for recording data and adaptation of research methods to the objectives of each experiment.

During the process of implementing the FPR-FFS in Peru, the quality of the programs was improved based on farmer suggestions. Educational activities needed to be adjusted for late blight management in potatoes compared with rice management. Decisions in potato IPM are longer term and damage to tubers is not easily detected. Midterm corrections included improvements to the IPM program for coverage of more issues, more tailoring to local needs and interests, and revision and restructuring of the Field Guide to make it more flexible. Following these revisions, the Field Guide was completed and formally published (1).

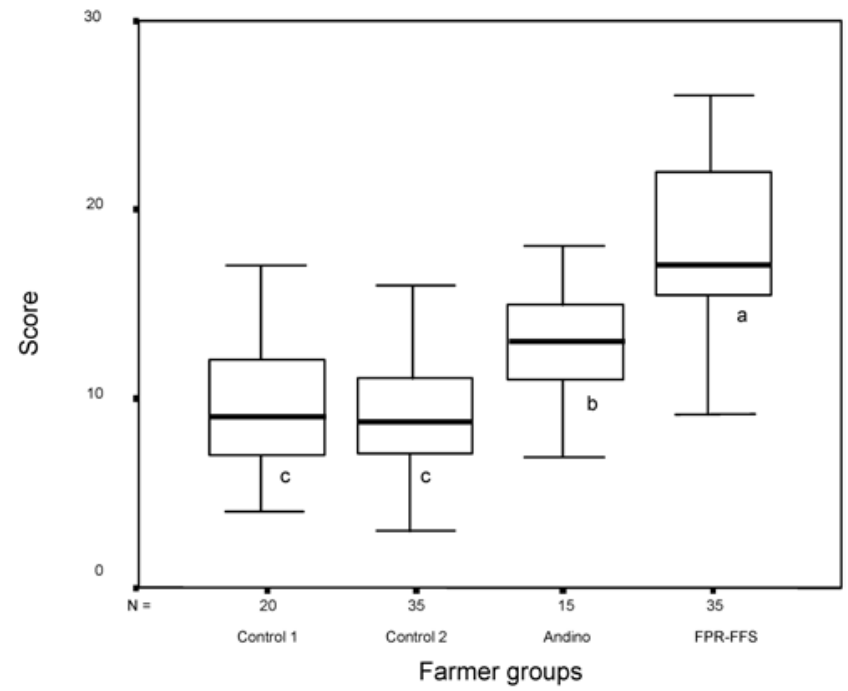

Fig. 1. Scores on an exam given during the 1999-2000 cropping season in San Miguel, Peru, over material taught in the local farmer field school (FFS) program. The exam consisted of 27 questions taken from the FFS field guide. The black line within the boxes indicates the mean, the box covers $50 \%$ of observations, and the lines indicate the range of scores. A Mann-Whitney U test indicated statistically different scores for the different groups. The Control 1 group was composed of 20 nonparticipant farmers in communities with FFS. The Control 2 group was composed of 35 nonparticipant farmers from communities without FFS. The Andino group was composed of 15 participants in the technical assistance project "Andino" who had received conventional extension training. The FFS group was composed of farmers who have participated in FFS (8).

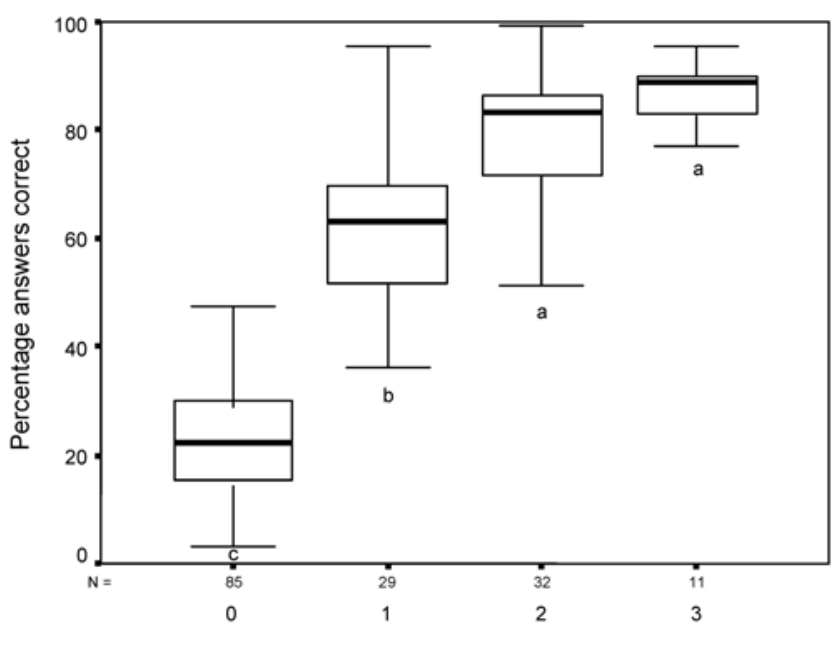

Years of participation in FPR-FFS

Fig. 2. Scores on an exam given during the 1999-2000 cropping season in San Miguel, Peru, over material taught in the local farmer field school (FFS) program. The exam consisted of 27 questions taken from the FFS field guide. Results of the exam are presented in terms of length of time the person taking the exam had spent in an FFS program. The black line within the boxes indicates the median, the box covers $50 \%$ of observations, and lines indicate the range of scores. Letters indicate significance groupings based on a Mann-Whitney U test (data from Peru 2001); FPR = farmer participatory research. Based on results from 86 nonparticipants, 29 respondents with 1 year of participation, 32 respondents with 2 years of participation, and 11 respondents with 3 years of participation. 
Clearly, FPR-FFS programs can provide a wide range of benefits. The direct benefits to participants in the programs may include improved decision-making abilities for late blight management and improved access to potato cultivars that are well suited to the local environment. Members of the community who did not participate directly in the FPR-FFS may also benefit to some degree because they, too, have increased access to locally adapted cultivars and exchange of information with participants. The community as a whole benefits from having regular community gatherings to address topics of mutual interest. Of the 20 FPR-FFS implemented in San Miguel, 16 decided to continue meeting regularly in FFS groups facilitated by farmer-facilitators after the formal program had concluded. Farmers are taking steps to formalize an association of FFS through which they could continue working on other topics such as problems in livestock management. The more generalized benefits of FPR-FFS programs may include improved estimates of the performance of management techniques and new germ plasm and cultivars, both in particular environments and in the region as a whole. Breeding programs that have access to information about the performance of crop genotypes in more locations and more different types of locations may benefit from improvements to both the precision and range of their estimates of genotype performance. The precision of an overall estimate of performance may be improved and the range of environments for which performance can be estimated is expanded.

Evaluating the direct benefits of FPRFFS for the immediate participants. At least two different approaches can be taken for measuring the direct benefits for the field school participants. One approach is to estimate how much participants know about crop and disease management compared with nonparticipants, an indicator of enhancements to human and social capital because group action is strengthened (3). The enhancement of these types of capital at the community level seems to be a prerequisite for the adoption of knowledgeintensive technologies such as IPM. It might be assumed that this knowledge often leads to improved management decisions that would result in greater shortterm economic returns for participants and also, potentially, greater long-term stability in productivity and greater safety for farmers applying pesticides. A second approach is to estimate the potato yields obtained by participants compared with nonparticipants. This approach more directly addresses the short-term productivity gains for participants in FPR-FFS.

The first approach was taken in an evaluation of the Peruvian FPR-FFS program in 2000 using a survey. This survey was completed by 20 nonparticipants from
FFS communities, 35 nonparticipants from non-FFS communities, 15 participants in programs with other training strategies, and 35 FFS participants. The survey was composed of 27 questions taken from the curriculum of the FFS. The questions covered such topics as the origin of late blight, dissemination, inoculum sources, control methods, and fungicide use. The results of this survey showed that participants in the program did know the material covered in the program better than nonparticipants (Fig. 1). A 2001 survey also tested farmers' knowledge of the material from the program as a function of the number of years of participation in the program. The results indicated that an additional year of participation past the first year was beneficial for increasing knowledge of the FFS material, but that a third year was not cost effective (Fig. 2).

It may be possible to identify particular concepts about a cropping system that are likely to lead most directly to improved management. For example, different late blight management strategies can be followed depending on whether susceptible or resistant cultivars are being grown. One concept covered in the FPR-FFS program was the potential to use fewer fungicide applications when managing late blight in resistant cultivars. In a 2001 survey of 158 San Miguel farmers, participants in the

Table 1. Results from a survey of farmers in San Miguel, Peru, who either were (72 respondents) or were not (71 respondents) farmer field school (FFS) participants ${ }^{\mathrm{a}}$

\begin{tabular}{lcc}
\hline Technique & Participants (\%) & Nonparticipants (\%) \\
\hline Same management for resistant and susceptible & 29 & 79 \\
Fewer fungicide applications for resistant & 71 & 21 \\
\hline
\end{tabular}

${ }^{a}$ Farmers were asked whether the number of fungicide applications should be the same for resistant and susceptible cultivars. Farmers tended to think that resistant and susceptible cultivars should be managed the same prior to FFS participation (14).

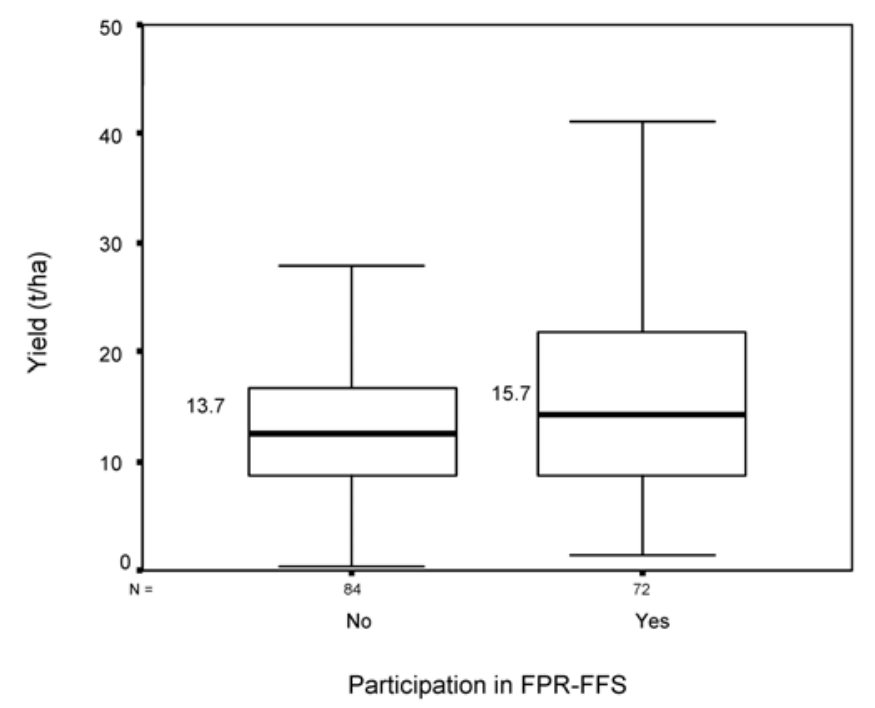

Fig. 3. Potato yield for farmer field school participants and non-participants in San Miguel, Peru (2000-2001 cropping season). Black lines inside boxes indicate the median, boxes cover $50 \%$ of observations, and outer lines indicate the range of scores. Numbers indicate the average yield per group, which were found to be significantly different using a $t$ test (adapted from 14); FPR-FFS = farmer participatory research- farmer field school program. 
nonparticipants include the need for realistic control groups. Farmers who are interested in participating in FPR-FFS programs may be those who already are more knowledgeable and more motivated to gain knowledge. Farmers who are willing to participate in studies, even as nonparticipant control groups, may be more knowledgeable and motivated than the average farmer, though a study by Godland et al. (7) reported no significant differences between FFS participants and nonparticipants in San Miguel in terms of socioeconomic characteristics such as education.

An indirect measure of the benefits to participants in a FPR-FFS program is the sustainability of the program, assuming that participants are more likely to support programs that they find useful. When the FPR-FFS program began in San Miguel in 1997, CIP-CARE took most of the responsibility for programs. Since then, farmers have been trained as facilitators and responsibility for programs is shifting so that farmers now have the greater responsibility for programs. In 2002, 12 out of 16 FPRFFS were facilitated by farmers. Farmer facilitators were trained to help bring about this shift in responsibility, allowing the programs to continue at a reduced personnel cost.

Evaluating the benefits of FPR-FFS for the development of improved cultivars and IPM approaches. In evaluating the benefits for the development of cultivars and recommendations for techniques, we again can consider less-direct and more-direct evaluations. Less-direct evaluations include those that estimate how much information has been gained by the inclusion of additional FPR-FFS sites. Traditionally, the development of cultivars (or management techniques) may be based on evaluation of performance at only a small number of managed research stations. Additional information from FPRFFS networks can be beneficial for estimating performance both through the general statistical benefit of additional data and also because the estimates are based on the conditions in which farmers work. Research stations may have access to better land and better management than the average farmer. The large number of sites available for study as part of the FPR-FFS network also allows disease to be studied in a great range of environments within a single season. Areas such as the Peruvian Andes experience huge differences in environment over small distances (Fig. 4) and these differences are reflected in the range of disease severity at the different Peruvian FPR-FFS sites. For example, in communities located at $2,800 \mathrm{~m}$, such as Lanchepampa, light blight severity is much higher than for communities such as $\mathrm{El}$ Empalme, located at 3,300 m. In the 19992000 season, each set of breeding lines was tested by 3 to 4 communities, and a three- to sevenfold difference in average area under the disease progress curve was observed among sites for a given set (CIP, CARE-Peru, and farmer groups, unpublished data). A more direct measure of benefits is the success of new cultivars or techniques that have been promoted as a result of their success in FPR-FFS and that might not otherwise have been promoted. Evaluating this form of benefit may require a number of years of observations.

The development of potato cultivars in conjunction with the FPR-FFS sites in Peru followed the following progression. As part of CIP's breeding activities, crosses made in 1996 were reduced to the 5,000 best clones; in 1997, these were reduced to the best 500 clones; and, in 1998, these were reduced to the best 50 clones. The best 25 clones of the $\mathrm{B}_{3} \mathrm{C}_{1}$ population were included in breeders' trials and in FFS trials in 1999 and 2000 for selection of the best 10 clones in 2001-02. Inclusion of the clones in FFS studies allowed evaluation in 20 more communities than otherwise would have been possible.

A potentially very important benefit of including more sites through participation of FFS groups is the increase in the chance of early detection of the breakdown of resistance while the new pathogen genotypes may not yet be widely dispersed. The importance of this benefit also may be difficult to evaluate in the short run. In addition, there are at least two other components to benefits from having more siteyears included in an analysis of the performance of a cultivar or technique. First, more site-years will allow a better estimate of the overall performance of a particular technology (13); this component will be discussed in more detail below. Second, more site-years will allow consideration of which technologies may be specialized; that is, which cultivars or techniques may be better adapted to some sites and less adapted to others. How large is the advantage of a local recommendation compared with the overall recommendation? This second question deals with the direct benefit to individual communities from the opportunity to select cultivars more specifically adapted to their local environments. We are in the process of developing an analysis to compare cultivar recommendations within a location to the overall cultivar recommendations. Our goal will be to estimate the extent to which locally recommended cultivars outperform those that would be recommended based on a

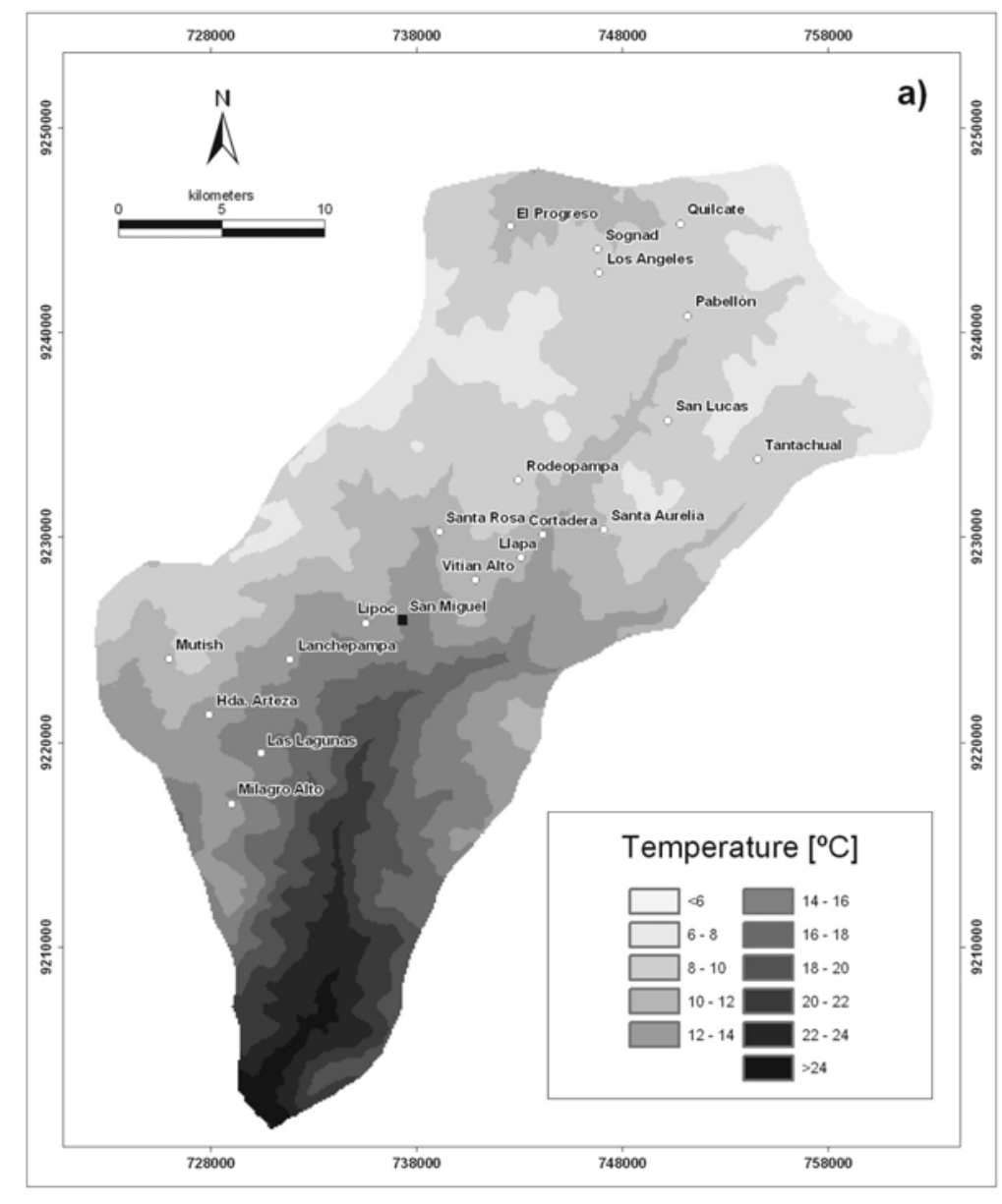

(continued on next page)

Fig. 4. Meteorological and micrometeorological data for San Miguel, Peru, during January to April 2001; A, temperature, B, relative humidity, C, leaf wetness duration. Weather data were interpolated using a Digital Elevation Model-DEM (adapted from 12). 


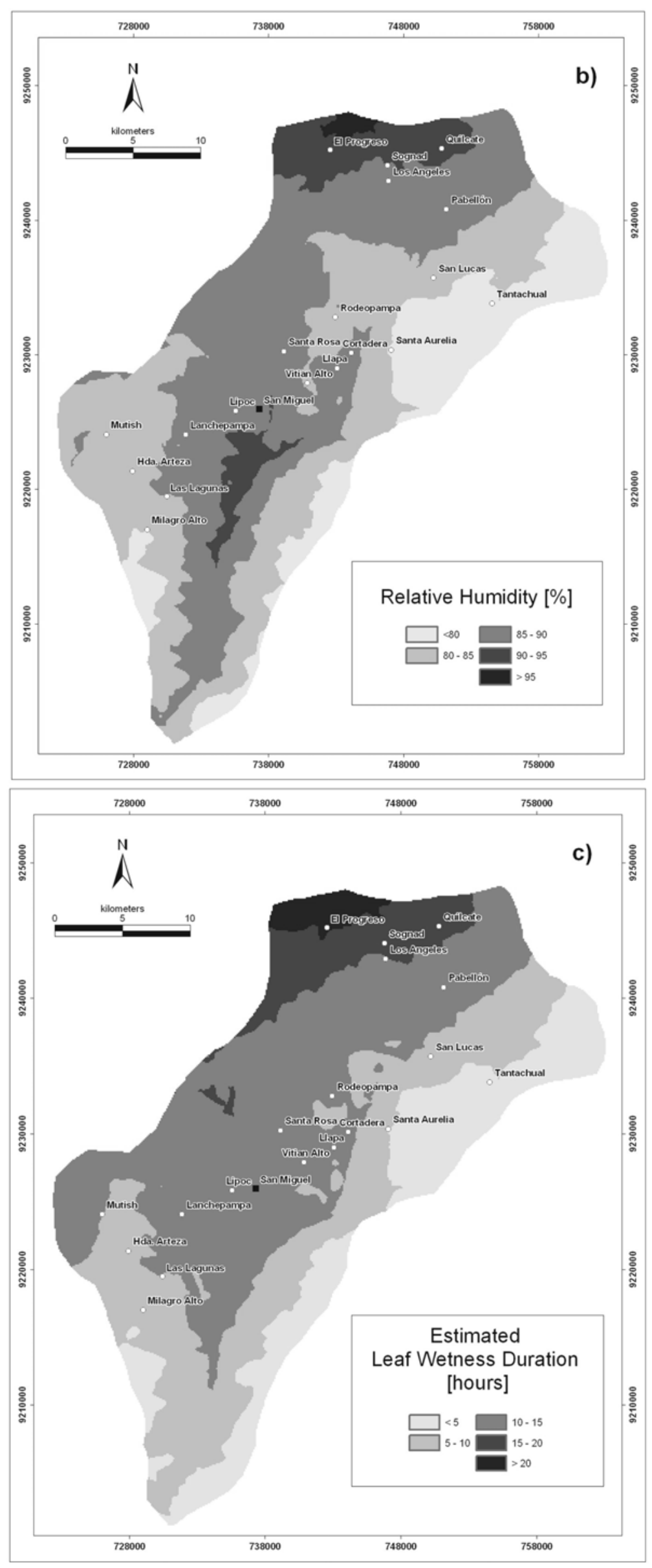

Fig. 4. (continued from previous page) regional or overall performance index. This will be one measure of the benefit to a community of having the opportunity to test cultivars for itself rather than relying on overall recommendations.

To illustrate consideration of the first component, the overall performance of a cultivar or technology, we analyzed the data sets from the Peruvian FPR-FFS programs. Most site-years in this study included the standard cvs. Amarilis (moderately resistant to late blight), Yungay (moderately susceptible), and Tomasa Condemayta (highly susceptible). As one measure of the benefit to the overall estimate of performance of these cultivars from including more site-years in the estimate, we performed the following computational resampling analyses using a custom script written in MatLab (v. 6.0; MathWorks, Natick, MA). We calculated the mean yield of each cultivar by sampling between 1 and 42 site-years for Amarilis and Yungay and between 1 and 39 site-years for Tomasa Condemayta. For example, to calculate the yield estimate based on a single site-year, the estimates for Amarilis yield from each site-year were assembled to produce the collection of single site-year estimates. For the two-site-year estimates for Amarilis, yield of Amarilis from pairs of site-years was averaged to produce an estimate and these estimates made up the collection of two-site-year estimates. Similarly, for the three-site-year estimates, estimates were the mean from triplets of site-year yields. These estimates were plotted for each of the three standard cultivars as a function of the number of site-years contributing to the estimate (Figs. 5 and 6).

Two different versions of this analysis were performed. In the first, the absolute yield estimates were used for the calculation. Because the average yield varied greatly from site-year to site-year, estimates based on the mean absolute yield from a small number of site-years were highly variable. This analysis is informative, but exaggerates the problem of estimates based on low numbers of site-years somewhat because the most important point is the relative performance of cultivars at a site (Fig. 5). We also performed a second analysis to consider more directly how relative yield performance differs from site-year to site-year and how much an estimate of overall relative yield performance may be improved by inclusion of more site-years. In this analysis, the yield of each cultivar at each site-year was standardized by dividing by the average yield of the three standard cultivars for that site-year before being included in the resampling analysis. Then the estimates were calculated as for the absolute yield estimates (Fig. 6).

The results of these analyses can be interpreted in terms of how the variability of estimates changed as more site-years were included in producing the estimate. The variability in estimates (Figs. 5 and 6, the 
vertical scatter) declined as a larger number of site-years were used to produce the estimate. For the analysis of absolute yield, after approximately 15 to 20 site-years were included, the benefit from adding additional site-years became small. For the analysis of relative yield, the benefit of adding additional site-years became small after 10 to 15 site-years were included. However, additional site-years might still contribute very useful information for participants if performance of a cultivar or technique tends to be site-specific.

One of the more direct measures of the immediate benefits of input from FPR-FFS programs to the development of new cultivars is the extent to which new cultivars are released based on the response of farmers in FPR-FFS programs. FPR-FFS also can prove useful for screening the success of clones in more challenging environments than might be present in the experimental farms used by breeders. As an example, two clones that might otherwise have been considered promising were rejected due to tuber deformation and low or unstable yield in some Peruvian FPR-FFS environments. These rejected lines were submitted by two institutions, in each case accompanied by lines that performed well and were subsequently released, suggesting that the institutions lacked sufficient information to discriminate the better- and worse-performing lines. Input from farmers also can lead to clones being screened quickly if they are not attractive in terms of harvest characteristics or tuber characteristics and culinary quality. As an example of

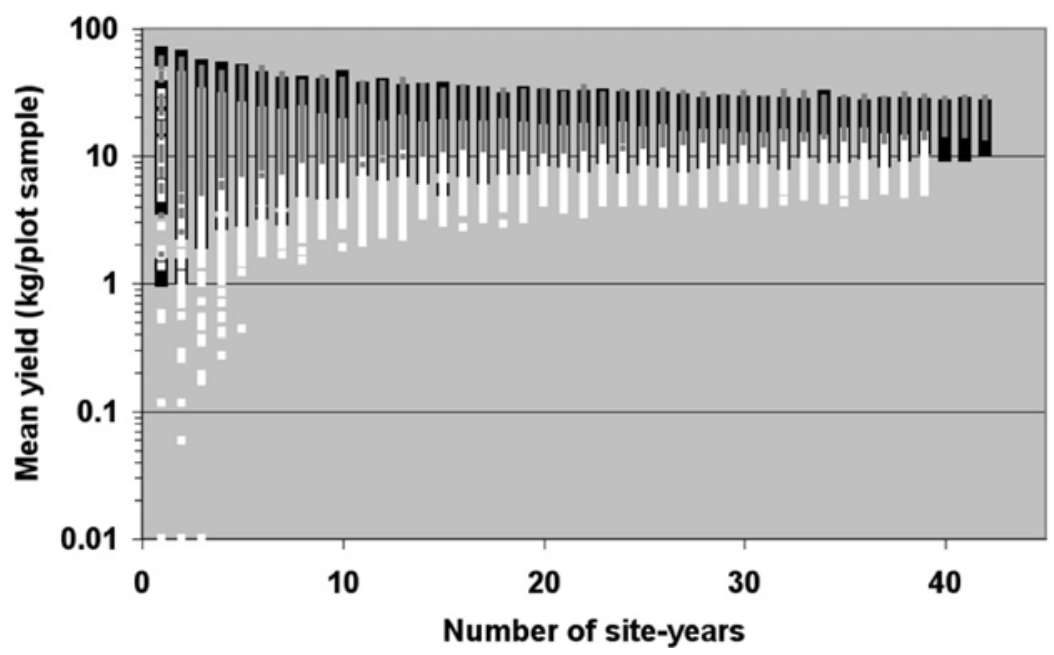

Fig. 5. Estimates of the mean yield for each of three standard potato cultivars, Amarilis (gray), Yungay (black), and Tomasa Condemayta (white), as a function of the number of farmer field school (FFS) sites-years included in constructing the estimate. Data included in this analysis were from a total of 5 FFS in San Miguel and 20 in other parts of Peru in 1997, 1999, 2000, and 2001. The reduced variation in estimates (reduced vertical spread) is a measure of improvement in the estimate as a function of the inclusion of more FFS sites.

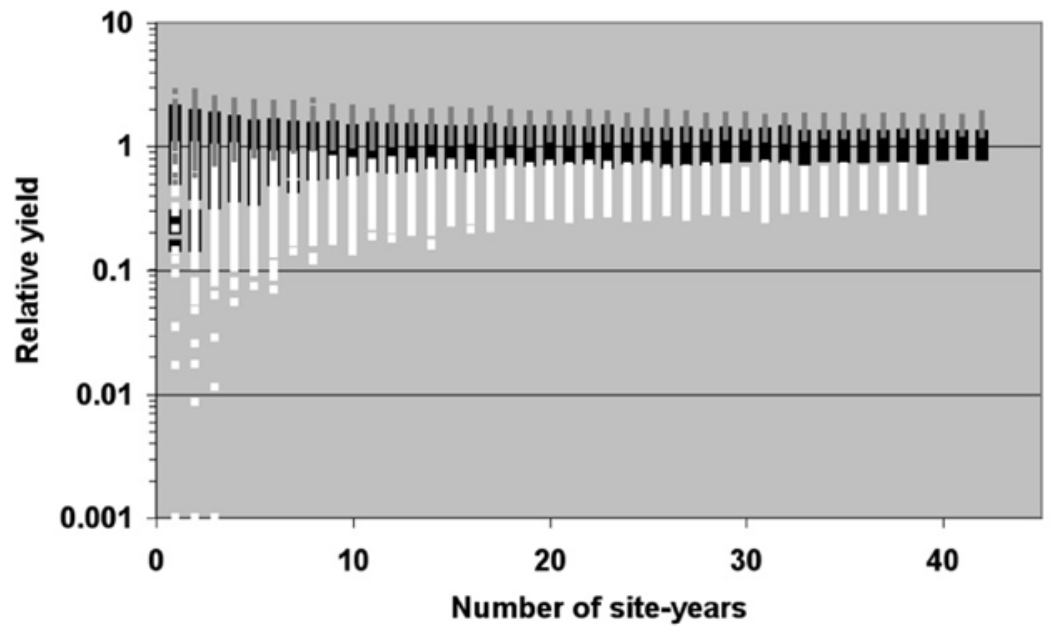

Fig. 6. Estimates of relative mean yield for each of three standard potato genotypes, Amarilis (gray), Yungay (black), and Tomasa Condemayta (white), as a function of the number of farmer field school (FFS) site-years used in constructing the estimate. Data included in this analysis were from a total of 5 FFS in San Miguel and 20 in other parts of Peru in 1997, 1999, 2000, and 2001. The reduced variation in estimates (reduced vertical spread) is a measure of improvement in the estimate as a function of the inclusion of more FFS sites. the success possible from input from FPRFFS, three cultivars were released in 19992000 by National Agricultural Research Systems in Peru from lines that received positive ratings in the FPR-FFS program. In this case, farmers confirmed recommendations based on several years of evaluation in other parts of Peru. The inclusion of farmer participation in breeding efforts may accelerate the selection and adoption of new cultivars because valuable materials are entered immediately into informal seed production systems. In 2002, $4 \%$ of the potato production area in San Miguel was planted with clones selected through this program that farmers had multiplied from small quantities of seed initially introduced through FPR-FFS trails. Seed multiplication rates are low for potato (compared with cereal crops, for example) and it will be useful to evaluate follow-up information to determine how well these new cultivars perform in future years. Another evaluation of benefits from FPR-FFS could be based on how much greater the economic performance of these cultivars proves to be compared with other cultivars that have been developed with less input from farmers.

In conclusion, FPR-FFS projects can generate several types of benefits. Participants can benefit from enhanced knowledge and higher productivity in addition to improved community organization. Local and regional estimates for the selection of cultivars and management techniques can be improved by information from a wider range of sites. Extension organizations also can benefit from experience with participatory methods and examples of how recommendations can be adapted to local environmental conditions. FPR-FFS offers an option for using scarce resources more efficiently.

\section{ACKNOWLEDGMENTS}

We thank the farmers of San Miguel; J. Tenorio, C. Valencia, H. Cisneros, V. Leon, M. Bazán, M. Cerna, and E. Baca of CARE-Peru; C. Fonseca, J. Landeo, A. Lagnaoui, and M. Palacios of CIP; K. Gallagher and M. Taguchi of the FAO Global IPM facility; D. C. Adams of Iowa State University; T. C. Todd of Kansas State University; and J. L. Heath.

\section{LITERATURE CITED}

1. Bazán, M., Castillo, R., Fonseca, C., Lagnaoui, Z., León, J. C., León, W., León, V., Nelson, R., Orrego, R., Ortiz, O., Palacios, M., Salazar, E., Silva, C., Tenorio, J., and Valencia, C. 2002. Guía para facilitar el desarrollo de escuelas de campo de agricultores. Manejo integrado de las principales enfermedades e insectos de la papa. CIP-CARE. Lima, Perú.

2. Bentley, J. 1989. What farmers don't know can't help them: the strengths and weaknesses of indigenous technical knowledge in Honduras. Agric. Human Values Summer:25-30.

3. Buck, A. 2001. Participatory evaluation of farmers' perceptions about impact of Farmer Field Schools - case study Province San Miguel, Peru. Thesis, Technical University of Munich.

4. Garrett, K. A., and Dendy, S. P. 2002. Prácticas culturales para el manejo del tizón tardío de la papa. Pages 111-120 in: Complementando la Resistencia al Tizón (Phytophthora infestans) 
en los Andes. E. N. Fernández-Northcote, ed. Global Initiative for Late Blight, Lima, Peru.

5. Garrett, K. A., and Mundt, C. C. 2000. Host diversity can reduce potato late blight severity for focal and general patterns of primary inoculum. Phytopathology 90:1307-1312.

6. Garrett, K. A., Nelson, R. J., Mundt, C. C., Chacon, G., Jaramillo, R. E., and Forbes, G. A. 2001. The effects of host diversity and other management components on epidemics of potato late blight in the humid highland tropics. Phytopathology 91:993-1000.

7. Godland, E., Sadouler, E., de Janvry, A., and Margai, R. 2001. Testing the impact of farmerfield-schools on knowledge: An empirical study of potato farmers in the Peruvian Andes. Annual Meetings of the American Agricultural Economics Association, Chicago.
8. Nelson, R. J., Orrego, R., Ortiz, O., Mundt, M., Fredrix, M., and Vien, N. V. 2001. Working with resource-poor farmers to manage plant diseases. Plant Dis. 85:684-695.

9. Ortiz, O., and Valdez, A. 1993. Enfoque de sistemas y metodología participativa para desarrollar medios escritos de comunicación agrícola. El caso de la papa en la agricultura de subsistencia. Rev. Latinoamericana de la Papa 5/6:103-121.

10. Ortiz, O., Winters, P., and Fano, H. 1999. La percepción de los agricultores sobre el problema del tizón tardío o rancha (Phytophthora infestans) y su manejo: Estudio de casos en Cajamarca, Perú. Rev. Latinoamericana de la Papa 11:97-120.

11. Roling, N., and Van de Fliert, E. 1994. Transforming extension for sustainable agriculture. The case of integrated pest management in rice in Indonesia. Agric. Human Values 11(2-3):96-108.

12. Troost, T. 2002. Spatial variation in Late Blight severity (Phytophthora infestans) in potato crops in relation to climate and crop management. M.Sc. thesis. Wageningen University, Wageningen, Netherlands.

13. Witcombe, J. R., Virk, D. S., and Raj, A. G. B. 1998. Resource allocation and efficiency of the varietal testing system. Pages 27-43 in: Seeds of Choice: Making the Most of New Varieties for Small Farmers. J. R. Witcombe, D. S. Virk, and J. Farrington, eds. Oxford \& IBH Publishing Co., New Delhi, India.

14. Zuger, R. Impact Assessment of Farmer Field Schools in Cajamarca. An Economic Evaluation. Working paper, Social Sciences Department, International Potato Center. In press. 